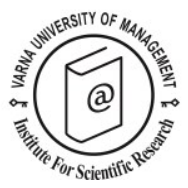

\title{
Humour in Customer Engagement on Chinese Social Media - A Rhetorical Perspective
}

\author{
Jing $\mathrm{Ge}^{1}$
}

Received: 19/12/2016

${ }^{1}$ Laboratory for Intelligent Systems in Tourism, USA; email: jingge@mkt-ai.com

Supervisors: Professor Ulrike Gretzel, University of Southern California, USA Associate Professor Yunxia Zhu, The University of Queensland, Australia

Institution awarding the Ph. D. Degree: The University of Queensland, Australia

Date of defence: 26/09/2016

(C) 2017 Varna University of Management. All rights reserved

Citation: Ge, J. (2017) Humour in Customer Engagement on Chinese Social Media - A Rhetorical Perspective. Doctoral Dissertation Summary. European Journal of Tourism Research 15, pp.171174

\section{Goal and objectives of the dissertation} Goal

To develop a framework of customer engagement through humour on social media, which embraces both firm-initiated activities and customers' reactions in the context of destination marketing on the Chinese social media platform Weibo.

\section{Objectives}

1. To develop a taxonomy to systematically classify and map firm-initiated humour strategies aimed at engaging customers in social media conversations.

2. To describe and categorise the respective customer responses to these persuasive firm posts.

\section{Methodology}

Rhetorical analysis was adopted as the methodology to allow for an in-depth examination of customer engagement on social media from a persuasion perspective. Specifically, this research adopted the rhetorical triangle, comprising of author, text and audience (Burke, 1969), to analyse firmcustomer conversations involving humour. The author position in the triangle refers to both firms who initiate humour posts and customers who publish comments. The text consists of messages as well as social media-afforded modalities (e.g. photos, hashtags and emojis). The audience includes firms, specific customers and general social media users at which the posts and subsequent comments are directed. Data collection for taxonomy development in the main study occurred from 25 October 2014 to 28 December 2014. It included two phases: 1) selecting all firm-initiated conversations that took place from 10 September 2014 to 10 October 2014; and 2) selecting firm-initiated conversations involving humour $(n=271)$ and respective customer responses ( $n=1013)$. Following the same process, additional data, including 25 firm-initiated humour posts published in March 2016 and respective customer verbal responses $(n=158)$, was collected to confirm the taxonomy. A mixed approach to taxonomy development, including 
three-phase data analysis, was used. The first phase - conceptual to empirical analysis identified firm-initiated humour strategies and respective consumer responses by applying the conceptual framework developed on the basis of persuasion and humour theories. The second phase - empirical to conceptual analysis analysed the leftover data. The third phase re-conceptual to empirical analysis - applied the expanded conceptual model to new data and was able to confirm the established taxonomy.

\section{Results}

First, the findings reveal a large array of social media-afforded verbal and non-verbal interactions through which firm-customer conversations are structured and sustained. Second, various types of firm-initiated and customer-responded humour posts/comments were identified, and evidence of humour coconstruction on social media was revealed. Third, distinct rhetorical appeals embedded in firm-initiated humour were found, depicting the means through which firms, and in particular destination marketing organizations, use humour to generate customer responses. Finally, interesting patterns of multimodal forms of text were found in these conversations, shedding light on social media-afforded multimodalities.

\section{Theoretical Conclusions}

The research findings are significant in that they make an original contribution to social media marketing and tourism marketing literature, as well as to the four theoretical streams of 1) customer engagement; 2) humour; 3) persuasion; and 4) social media affordances. The strength of the research lies in developing important conceptualizations and in presenting taxonomies that advance our understanding of customer engagement on social media and provide critical support for future research in these areas.

\section{Practical applications}

Given the increasing challenges of marketing on social media (Gretzel and Yoo, 2013), knowledge about engaging customers on these platforms is critical. The results offer strategic implications for social media marketing, with a specific focus on destination marketing. This dissertation also has wider implications for the implementation of cross-cultural communication and value co-creation in the context of social media marketing. Moreover, the taxonomies offer firms fundamental knowledge about how to orchestrate customer-dominated conversations, and how to strategically use humour and the technological basis of social media. This study also has concluded that firms face a few critical challenges when using humour to engage customers on Chinese social media, because it is intertwined with cultural, social and political issues. An intrinsic understanding of what can be used, what cannot be used and how to use it is paramount.

\section{Content of the dissertation}

Abstract of chapter one

With the paradigm shifts towards the empowerment of consumers facilitated by social media, it has become evident that traditional approaches to customer engagement have undergone a substantial change. Scholars have questioned the existing theoretical foundation of customer engagement, and advocate the need to understand how it is structured and enabled in the specific context (Russell, 2009). In synthesising the current gaps in knowledge, this dissertation recognises the need for a re-conceptualisation of customer engagement.

\section{Abstract of chapter two}

The notion of customer engagement and the persuasive power of humour to engage customers have become of primary importance for tourism research and practice (Gretzel and Yoo, 2013; Pearce and Pabel, 2015). However, customer engagement is transformed from oneway communication with a firm focus in traditional media to customer-dominated twoway conversations on social media (Gretzel and Yoo, 2013). Besides, humour use for marketing purposes has changed from a focus on providing cognitive cues in one-way persuasion processes (Eisend, 2011) to a rhetorical tool through which firms can create affiliation with customers (Meyer, 2000). While the literature has recognised these paradigm shifts in the context of social media, a holistic understanding of this phenomenon is still missing to date. The main contribution emerging from the literature review is that it interlinks the four dominant 
literature streams of customer engagement, social media affordances, humour along with Chinese humour and persuasion.

\section{Abstract of chapter three}

To answer the critical questions related to customer engagement through social mediaafforded conversations and humour, this study adopts a rhetorical perspective and develops a conceptual framework to investigate this new phenomenon. First, firm-customer conversations are structured through verbal moves which are realised through speech acts (Searle, 1969); customer responses are manifested through verbal (i.e. commenting) and social media-afforded moves (e.g. reposting). Second, the identification of humour co-constructed in firm-customer conversations is based on Berger's (1997) humour list, along with Chinese humour (Xue, 1989) as a complementary source. Both verbal moves and humour are delivered through social media-afforded multimodalities. Third, to generate customer responses, firms embed Aristotle's rhetorical appeals (i.e. pathos, ethos and logos) along with Chinese qing to their humourous posts. Finally, customers encapsulate sentiment in humour when responding to firm-initiated humour strategies.

\section{Abstract of chapter four}

To answer the research questions, rhetorical analysis was adopted; besides, a mixed approach to taxonomy development was deployed to identify and classify firm-initiated and customer-responded humour strategies. Three phases of data analysis were conducted. Following a cyclical process (Bauer and Gaskell, 2000), this study initially selected humour posts published by five Chinese DMOs and customer responses to these posts on Sina Weibo to develop the taxonomy, followed by collecting more data to confirm the taxonomy. Furthermore, this research undertook a threestep coding process through manual coding and reliability checks. To overcome the limitations of widely adopted sentiment analysis approaches, a crowdsourced sentiment analysis was used to code customer sentiment.

\section{Abstract of chapter five}

The firm and customer-focused taxonomies derived from the three-phase data analysis reveal interesting firm-initiated humour strategies and customer-responded strategies. Firms formulate and implement seven types of verbal moves and adopt eight types of mixed modalities to deliver these verbal moves. They adopt and formulate twenty types of humour techniques in their verbal moves and use eight types of humour modalities to deliver these humour techniques. Moreover, firms embed rhetorical appeals along with nineteen types of persuasive cues involved in these appeals in the humour techniques to generate customer responses. From a customer's perspective, they implement response strategies through: 1) four types of social media-afforded moves; 2) four types of verbal moves; and 3) twelve types of a combination of verbal moves and social media-afforded moves. They adopt three types of modality to deliver the last two categories of response moves. In implementing verbal moves and a combination of verbal and social mediaafforded moves, customers convey positive neutral, negative and mixed sentiment; meanwhile, they construct twelve humour techniques within these four types of sentiment and often co-construct humour with the firms.

\section{Abstract of chapter six}

From a firm's perspective, the research data showed that while firms use humour strategies to create the possibilities of generating customer responses through humour, they seem to consider some of the humour strategies as more useful to initiate customer engagement than others. First, humour strategies delivered through expressive moves and expressive and directive moves are more prominent than those delivered through other verbal moves. These heavily adopted verbal moves shed light on the changed structure of customer engagement on social media in terms of the way firms interact with customers. Second, humour strategies formulated with puns, impersonation and metonymy are treated as the most promising strategies to publish the interesting content and to draw customer interest. The non-adoption of some humour techniques suggests that crafting and implementing humour strategies requires firms to have linguistic proficiency and to take the Chinese social media context into consideration. Third, persuasive strategies implement- 
ted through rhetorical appeals and Chinese qing indicate affection, sympathy, warmth, similarity and relevant to customers are considered as powerful strategies to encourage customers to participate in firm-customer conversations. The heavy adoption of the aforementioned humour techniques and rhetorical appeals indicates firm-initiated humour strategies are employed in recognition of the technological, social and cultural dynamics of customer engagement on social media.

To respond to firm-initiated humour strategies, the research data showed customers implement complex response strategies by choosing diverse responding moves entailing nuanced sentiment, suggesting that firminitiated humour strategies indeed have a great potential to generate customer response. As for nonverbal responses, firm-initiated humour strategies can encourage customers to like and repost humour posts, and to tag their peers in firm-customer conversations. In terms of verbal responses, firm-initiated humour strategies can generate customer comments and combined comment and nonverbal responses (that is, tagging, reposting). In addition, the largest percentage of positive sentiment and a larger percentage of neutral sentiment than negative and mixed sentiment also suggest that firminitiated humour strategies are promising to generate more valuable customer responses. Customer verbal responses entailing positive sentiment play a crucial role in understanding customers' genuine interests and reaching and connecting with prospective customers through a positive voice. Responses entailing neutral sentiment are critical in terms of acknowledging customer needs and confusion, and encouraging customer-generated information.

Customers co-construct some of the firminitiated humour techniques in their verbal responses, suggesting that firm-initiated humour strategies have the potential to maintain and amplify firm-customer conversations involving humour. When customers construct humour in their verbal moves, they assist firms to maintain humour conversations. When customers formu- late humour in combined verbal and social media-afforded moves, they help firms not only to maintain, but also to amplify humour conversations on social media. More specifically, when customers embed humour in these verbal moves involving positive and even natural sentiments, they provide firms with more benefits than maintaining and amplifying these conversations, such as enhancing the credibility of the firm-initiated humour posts and reaching customers with a well-regarded image.

\section{References:}

Bauer, M. W. and Gaskell, G. (2000). Qualitative Researching with Text, Image and Sound. London, England: Sage Publications Ltd.

Berger, A. A. (1997). The art of comedy writing.United State : Transaction Publishers.

Burke, K. (1969). A rhetoric of motives (vol. 111). U.S.: University of California Press.

Eisend, M. (2011). How humor in advertising works: A meta-analytic test of alternative models. Marketing Letters, 22(2), 115132.

Gretzel, U. and Yoo, K. H. (2013). Premises and Promises of Social Media Marketing in Tourism. In McCabe, S. (ed.) (2013) The Routledge Handbook of Tourism Marketing. New York: Routledge. 491504.

Meyer, J. C. (2000). Humor as a Double-Edged Sword: Four Functions of Humor in Communication. Commu-nication Theory, 10(3), 310-331.

Pearce, P. L. and Pabel, A. (2015). Tourism and humour. United Kingdom: Channel View Publications.

Russell, M. G. (2009). A call for creativity in new metrics for liquid media. Journal of Interactive Advertising, 9(2),44-61.

Searle, J. R. (1969). Speech acts: An essay in the philosophy of language (vol. 626) United Kingdom: Cambridge university press.

Xue, B. (1989). Soft Humour of Chinese 中国人的软聯默 中国科学出版社 China: China Science Press. 